\title{
Nucleotide sequence of a new lignin peroxidase gene GLG3 from the white-rot fungus, Phanerochaete chrysosporium
}

\author{
P.S.Naidu and C.A.Reddy* \\ Department of Microbiology and Public Health, and NSF Center for Microbial Ecology, Michigan \\ State University, East Lansing, MI 48824-1101, USA
}

Phanerochaete chrysosporium, a wood-degrading basidiomycete, produces a family of 6 to 10 closely related extracellular, glycosylated, heme proteins, designated lignin peroxidases (LIPs) which are a key component of the lignin degrading system of this organism (1). Sequence data with LIP cDNAs $(2,3,6)$ and genes (4-6) indicated that the LIP gene family contains a number of closely related genes. We present here the complete nt sequence and the deduced aa sequence of a new LIP gene GLG3. The gene is interrupted by 8 introns ranging in size from 50-60 bp. The gene encodes a 372 aa protein including a 28 aa signal peptide which ends in a Lys-Arg cleavage site. The sequence of the protein encoded by GLG3 is identical to that of the LIP isozyme $\mathrm{H} 8$ except for minor aa substitutions. The coding region of this gene has $>96 \%$ homology to the gene encoding the LIP isozyme $\mathrm{H} 8$ and to its allelic variant $M L-4$. Using differences in restriction fragment length polymorphism between $G L G 3$ and the other two genes, we analyzed the DNA from basidiosporederived homokaryotic strains and these results showed that $G L G 3$ is non-allelic to the gene encoding H8. Northern blotting analyses showed that $G L G 3$ is expressed only during secondary metabolism.

\section{ACKNOWLEDGEMENTS}

This research was supported by the Michigan Agriculture Experiment Station, and grant I ROI GM 39032-02 from the National Institutes of Health.

\section{REFERENCES}

1. Kirk,T.K. and Farrell,R.L. (1987) Annu. Rev. Microbiol. 41, 465-505. 2. de Boer,H.A., Zhang,Y.Z., Collins,C. and Reddy,C.A. (1987) Gene 60, 93-102; Corrigendum (1988), 69, 369.

3. Tien,M. and Tu,C.-P.D. (1987) Nature (London) 326, 520-523 Corrigendum (1987) Nature (London) 328, 74.

4. Zhang,Y.Z., Reddy,C.A. and Rasooly,A. (1990) Gene (In press).

5. Schalch,H., Gaskell,J., Smith,T.L. and Cullen,D. (1989) Mol. Cell. Biol. 9, 2743-2747.

6. Andrawis,A., Pease,E.A., Kuan,I.-C., Holzbaur,E. and Tien,M. (1989) Biochem. Biophys. Res. Commun. 162, 673-680.

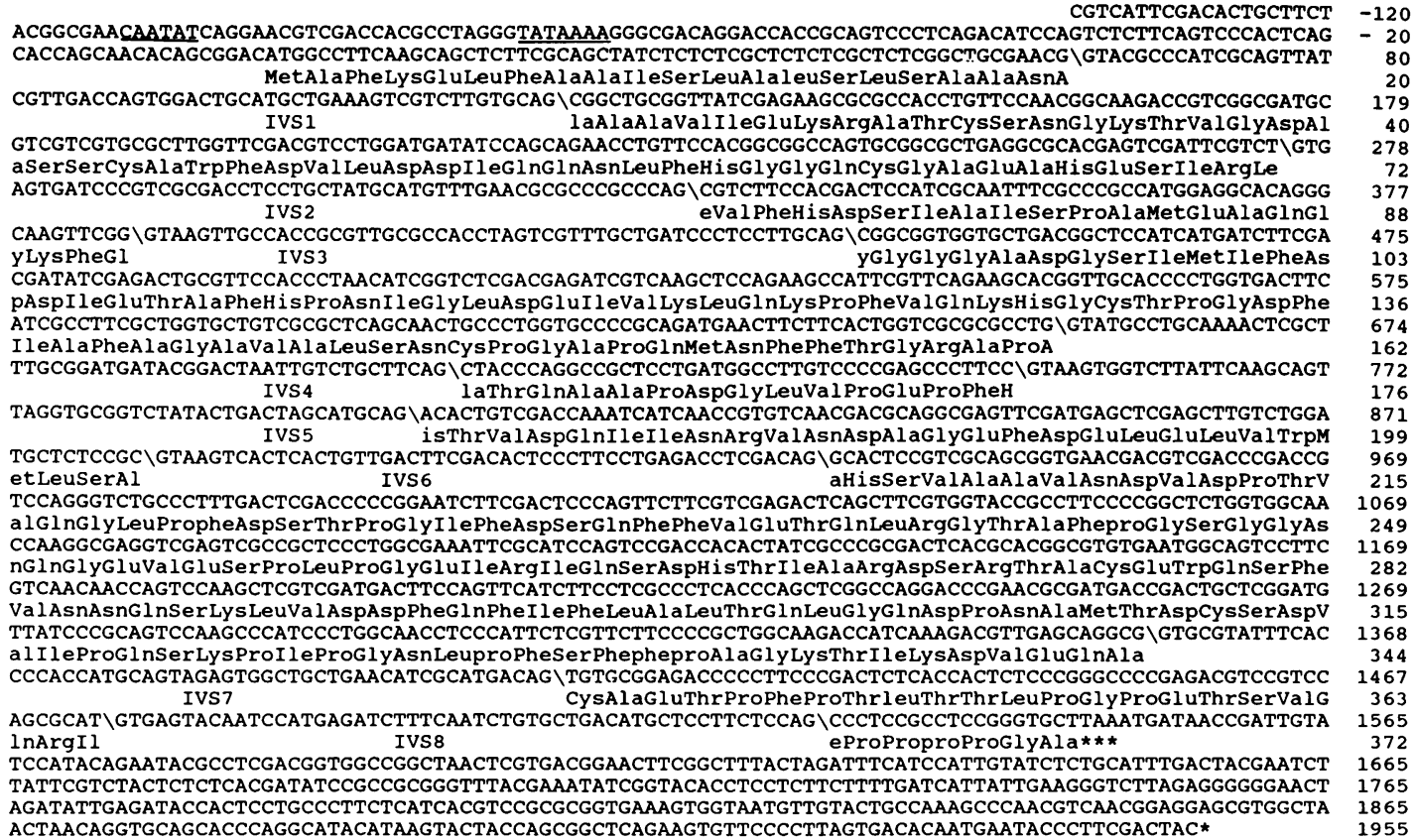

* To whom correspondence should be addressed 